\title{
ARTIFICIAL INSEMINATION AND INDUCTION OF PREGNANCY IN THE MONGOLIAN GERBIL (MERIONES UNGUICULATUS)
}

\author{
J. T. WU \\ Worcester Foundation for Experimental Biology, \\ Shrewesbury, Massachusetts 01545, U.S.A.
}

(Received 25th September 1973)

Although Marston \& Chang (1965) have noted that the Mongolian gerbil breeds best by monogamous pairing, mating is always unpredictable even when a pro-oestrous female is caged with a male. This causes great difficulty in obtaining a reasonable number of pregnant animals for experimental purposes. The present study was intended to investigate the feasibility of artificial insemination and induction of pseudopregnancy in the Mongolian gerbil in order to obtain a desired number of pregnant animals.

The female Mongolian gerbils of the Worcester Foundation stock and the Tumblebrook Farm stock (West Brookfield, Massachusetts), $2 \frac{1}{2}$ to 7 months old, were maintained in animal quarters at 20 to $24^{\circ} \mathrm{C}$, under artificial light from 07.00 to 19.00 hours. They were provided with oatmeal, Charles River rat chow and water, supplemented twice weekly with vegetables or apples.

The females usually came into pro-oestrus 2 to 3 days after an intraperitoneal (i.p.) injection of 5 to 10 i.u. PMSG (Sigma Chemical Co., St Louis) given during metoestrus or dioestrus. To ensure ovulation, the gerbils received an i.p. injection of 1.5 to 5 i.u. HCG at 13.00 to 14.00 hours on the day of prooestrus. At 15.30 to 17.30 hours, the animals were anaesthetized with sodium pentobarbital $(60 \mathrm{mg} / \mathrm{kg})$; the uteri were exposed through a mid-line abdominal incision and 0.03 to $0.05 \mathrm{ml}$ of sperm suspension containing 5 to $11 \times 10^{6}$ spermatozoa was injected into the lumen of each uterine horn. The sperm suspension was prepared just before use by flushing one cauda epididymidis with $0.4 \mathrm{ml}$ Medium 199 containing 1000 units of penicillin $\mathrm{G} / \mathrm{ml}$, by means of a 30-gauge needle attached to a $1-\mathrm{ml}$ syringe. The males, 4 to 9 months old, were derived from the Worcester Foundation stock.

For the induction of pseudopregnancy, the uterine cervix was stimulated with a small plastic rod attached to the tip of an electric engraver which had been adjusted to provide suitable vibrations, as in the method described by De Feo (1966). A similar technique had been routinely used for the induction of pseudopregnancy in rats, with a success rate of over $95 \%$ (J. T. Wu, unpublished results). Each gerbil received three 1-min periods of cervical stimulation: once in the afternoon of pro-oestrus about 15 to $30 \mathrm{~min}$ before anaesthesia for artificial insemination, and twice the next day (= Day 1 ) at 09.00 to 10.00 and at 16.00 to 17.00 hours. 
The animals were killed on Days 9 to 12 and the number of implantation sites and the presence or absence of CL were recorded. If implantation had failed to occur, the uteri were flushed with $0.9 \% \mathrm{NaCl}$ solution for the recovery of unimplanted ova.

A total of sixty-eight females was used. The results can be divided into four groups with respect to the presence or absence of $\mathrm{CL}$ and implantation sites. In Group 1, thirty-two gerbils $(47 \%)$ had both CL and implantation sites. In Group 2, fourteen animals $(20 \%)$ had CL but no implantation sites or unimplanted embryos, apparently due to the failure of fertilization and/or degeneration of embryos. The seven gerbils $(10 \%)$ in Group 3 had no CL but unimplanted blastocysts were present, the majority with intact zona. The blastocysts were obviously undergoing a delay in implantation due to lack of CL and suitable uterine environment, as observed in prepubertal mice (Smithberg \& Runner, 1956). In Group 4, the fifteen gerbils (22\%) had neither CL nor embryos, probably due to failure of ovulation, CL formation, fertilization, and/or embryonic degeneration. Since the mean volume of CL increases from about $1 \mathrm{~mm}^{3}$ on Day 1 to 3 to $4 \mathrm{~mm}^{3}$ in animals with implantations on Day 8 onwards (Norris \& Adams, 1971), there was no difficulty in identifying the CL at autopsy (Days 9 to 12 ).

Only $67 \%$ of the gerbils treated had CL and, therefore, were either pregnant or pseudopregnant. This is much lower than the incidence (over 95\%) obtained in rats in our laboratory by the same method of cervical stimulation. Thus, the Mongolian gerbil appears to be less responsive to cervical stimulation than the rat.

There was no difference in the average number of implanted or unimplanted embryos (9.3 versus 9.4) when the gerbils were injected with 5 i.u. PMSG and 1.5 to 2.5 i.u. HCG (thirteen animals) or with 10 i.u. PMSG and 3 to 5 i.u. HCG (nineteen animals). This is greater than the number of eggs (6.6) normally shed (Marston \& Chang, 1965).

It appears that pregnancy can be successfully induced in only $50 \%$ of the gerbils treated. A better and more efficient method needs to be developed if it is to be practical.

This study was supported in part by grants from the National Institute of Child Health and Human Development (HD 03003) and from the Ford Foundation to Dr M. G. Chang, whose interest and guidance during the study were greatly appreciated by the author.

\section{REFERENCES}

De Feo, V. J. (1966) Vaginal-cervical vibration: a simple and effective method for the induction of pseudopregnancy in the rat. Endocrinology, 79, 440 .

Marston, J. H. \& Ghang, M. G. (1965) The breeding, management and reproductive physiology of the Mongolian gerbil (Meriones unguiculatus). Lab. Anim. Care, 15, 34.

Norris, M. L. \& Adams, G. E. (1971) Delayed implantation in the Mongolian gerbil, Meriones unguiculatus. 7. Reprod. Fert. 27, 486.

SmTthbeRG, M. \& RUNNER, M. N. (1956) The induction and maintenance of pregnancy in prepuberal mice. F. exp. Zool. 133, 441 . 